\title{
Network-Integrated Ship Automatic System and Internetworking to the Internet
}

\author{
Li-Der Chou \\ Associate Professor, Department of Computer Science, Chung Hua Polytechnic Institute, Hsin-Chu, Taiwan, 30067, \\ R.O.C. \\ Jeng Yih Juang \\ Professor, Department of Merchant Marine and Institute of Maritime Technology, National Taiwan Ocean University, \\ Keelung, Taiwan, 2024, R.O.C.
}

Follow this and additional works at: https://jmstt.ntou.edu.tw/journal

Part of the Electrical and Computer Engineering Commons

\section{Recommended Citation}

Chou, Li-Der and Juang, Jeng Yih (1996) "Network-Integrated Ship Automatic System and Internetworking to the Internet," Journal of Marine Science and Technology. Vol. 4: Iss. 1, Article 15.

DOI: $10.51400 / 2709-6998.2548$

Available at: https://jmstt.ntou.edu.tw/journal/vol4/iss1/15

This Research Article is brought to you for free and open access by Journal of Marine Science and Technology. It has been accepted for inclusion in Journal of Marine Science and Technology by an authorized editor of Journal of Marine Science and Technology. 


\section{Network-Integrated Ship Automatic System and Internetworking to the Internet}

Acknowledgements

The authors would like to thank the anonymous reviewers for their constructive criticisms and suggestions. 


\title{
NETWORK-INTEGRATED SHIP AUTOMATIC SYSTEMS AND INTERNETWORKING TO THE INTERNET
}

\author{
Li-Der Chou*, Jeng Yih Juang**
}

Keywords: shipboard LAN, survivability, communication cost.

\section{ABSTRACT}

Many automatic systems developed for the merchant ships are focused on the Unmanned Machinery Space (UMS), and therefore it is necessary to build a local area network (LAN) on the ship in order to integrate these automatic systems. By means of the Inmarsat satellite system, the shipboard LAN is interconnected with the terrestrial communication networks such as the Internet. In the paper, the shipboard LAN is designed from the view point of survivability, and three concepts to reduce the satellite communication cost for the interconnection of the shipboard LAN and the Internet are proposed. Finally, the way to implement the Internet electronic mail service via the Inmarsat system are presented.

\section{INTRODUCTION}

Automation in the merchant ships is an irreversible trend for the development of science, the improvement of the working environment, the safety of the crew, the increase in the efficiency, high reliability, fast reponsibility, and the decrease in the cost of maintenance and management. Moreover, the number of mariners is able to be further reduced in afully automatic merchant ship. Up to date, most of the researches about the automation in the merchant ships focus their attention on the Unmanned Machinery Space (UMS) [1,2], including the automatic systems in navigation, communications, engines, cargo charging and discharging, fire extinguishment, and safety. A merchant ship is composed of bridge, engine room, cabin, cargo holds, poop, wheel house, chart room, radio room, compass room, and other

Paper Received January, 1996. Revised June, 1996. Accepted June, 1996. Author for Correspondence: Li-Der Chou.

*Associate Professor, Department of Computer Science, Chung Hua Polytechnic Institute, Hsin-Chu, Taiwan, 30067, R.O.C.

**Professor, Department of Merchant Marine and Institute of Maritime Technology, National Taiwan Ocean University, Keelung, Taiwan, 2024, R.O.C. holds, according to the type of the ship, and many automatic systems are distributed over there. Therefore, how to integrate the automatic systems becomes very important especially for a large-scale merchant ship which is similar to a multi-storied building.

Computer networks have been maturely developed and successfully applied to many areas, such as home banking, automated newspaper, library, military, traffic control, remote control, and remote databases, to achieve the following goals: resource sharing, high reliability, saving money, and enhancing human-to-human communication [3]. In the recent researches, high performance networks, such as the Fiber Distributed Data Interface (FDDI) [4] and the Asynchronous Transfer Mode (ATM) [5], are continuously proposed and implemented. Unlike conventional networks, such as telephone and packet switching networks, these high speed networks are expected to provide the capability of supporting a wide range of services such as data, voice, video, teleconferencing, high-definition TV (HDTV), and video/document retrieval services [6,7]. Moreover, many new network services, such as videoon-demand (VOD) [8], are continuously introduced.

It is a good idea to build a local area network (LAN) in a merchant ship to connect and integrate the automatic systems. The officer can operate and manage the ship anywhere on the ship through the shipboard LAN without staying in the bridge. Moreover, the shipboard LAN can be interconnected with the terrestrial communication networks, e.g. the Internet which provides a number of services and databases, via the satellite communications, so that the passengers, scientists and mariners are able to keep contact with anyone in the world. Especially, nobody is capable of enduring the lack of Internet services today, even at sea.

Another advantage of internetworking the shipboard LAN and the Internet is that all engines, machines and instruments connected to the shipboard LAN can be remotely controlled and monitored by the specialists and experts in the service and mainte- 
nance center on land, as shown in Fig. 1. It is often the case that instruments are increasingly complicated in the automatic systems and troubles are hard to be directly released by mariners. Therefore, it is necessary to fix the breakdowns on ships by the senior experts on land through the interconnected network. Moreover, an emergency sick at sea is able to get diagnoses and directions from the doctors on land via the interconnected networks, or the so-called distance medical treatment.

The survivability of the shipboard LAN is especially important for ships at sea, and becomes a key factor in designing the shipboard network. In the next section, we will discuss the factors which must be considered for the shipboard network design, and design a template for the shipboard LAN according to the classification of traffic. In Section 3, we first introduce the world-wide satellite communications, and then propose three concepts to reduce the costs for the interconnection of the shipboard LAN and the Internet via satellites. The way to implement the electronic mail service on board is also proposed. Finally, the summary and future recommended works are given in Section 4.

\section{DESIGN OF THE SHIPBOARD LAN}

It is necessary to build a shipboard LAN for mariners and passengers. For mariners, the shipboard LAN is capable of providing the solution to integrate all of the automatic systems, so that these systems can be monitored and operated anywhere in the shipboard LAN. The acquisition datum for the environment of the ship, such as the position of the ship, the ship's speed and direction, pitching and rolling, the wind's speed and direction, the temperature of the sea surface, and the status of the automatic systems, are also collected and logged through the shipboard LAN. Furthermore, the automatic systems are

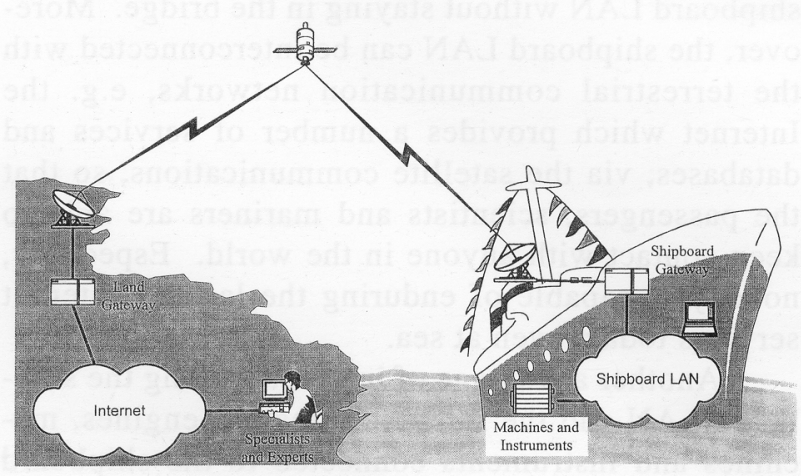

Fig. 1. An application of remote maintenance and diagnosis by the interconnection of the shipboard LAN and the Internet. also able to be remotely controlled from anyplace in the world as long as the shipboard LAN is connected to the Internet. Moreover, many useful databases [9], such as the weather report, the maritime geographical information system (MGIS), and the maritime safety information (MSI), and many Internet services are accessible through the interconnection of the shipboard LAN and the Internet. The method for the internetworking will be explained in detail in the next section.

On the other side, the merchant ship always provides many entertainment and daily-life services for the passengers. Some of the services, such as the video on demand, audio on demand, KTV, and shopping, can be implemented through the shipboard LAN. Passengers call and enjoy the services via the shipboard LAN instead of personally going to the entertainment houses and shopping stores. A comfortable and convenient life environment via the shipboard LAN will become a strong appeal to canvass for passengers and mariners.

After showing the importance of building a LAN on ships, we shall design a template for the shipboard LAN, where the performance factors of concern include the type of the merchant ship, the speed of response, survivability, traffic priorities and security. The physical network topology depends on the ship's structure which is related to the type of the ship. From the view point of speed, optical fibers are capable of offering high bandwidth, when compared with other transmission media, such as the coaxial cables and twist pairs. Hence the fibre optics are able to provide multi-media services including VOD, KTV and virtual shopping. Besides, optical fibers are capable of preventing from the interference of electric wave and the corrosion of sea salt. Moreover, Fibre optics have little effect on the survivability aspects of a network. Therefore, optical fibers are adopted due to their superiority. However, if the twist pairs have to be used for some reasons, the Shielded Twist Pairs (STP) are suggested.

Survivability is defined as the probability of the network providing a service in the presence of system and/or component faults [10]. Network faults may cause total collapse of the network where the survivability is out of consideration. Since at sea the support for a ship is limited and difficult, the collapse of the shipboard LAN not only paralyze the automatic systems on board, but also may endanger the lives of passengers and mariners. Thus survivability becomes the most important key factor in the design of the shipboard LAN.

According to the offered function, the traffic in the shipboard LAN can be classified into two types: 
type 1 for the automatic systems, and type 2 for the entertainment daily-life services. Obviously, the information carried by the type 1 traffic is with regard to the navigation, operation, maintenance and safety of the ship, and is always more important than other traffic types. Thus, high priority is assigned to the type 1 traffic. Moreover, most of the information carried by the type 1 traffic, except some basic navigation information, has to be secured to prevent from affecting the passengers.

All of the above factors have to be simultaneously considered during the design of the shipboard LAN. The general network topology is designed as shown in Fig. 2. Note that the realistic network topology also depends on the use, tonnage and type of the ship. The shipboard LAN is functionally divided into two subnetworks, the entertainment subnetwork and the automatic-system subnetwork, which are connected to the backbone via gateways. The gateways are capable of filtering traffic types. The automatic-system subnetwork with the gateway connected to the backbone have to be replicated for the reason of survivability and reliability. However, it is not necessary to replicate the entertainment subnetwork, since it is not as important as the automatic-system subnetwork.

Figure 3 shows the example for the design of the shipboard LAN. The whole structure of the shipboard LAN is composed of a star subnetwork and a ring subnetwork. The star subnetwork connects all of the automatic systems by point-to-point links to a common central unit, and is treated as the automatic-system subnetwork. The reason to adopt the star topology is that the effect of faults is very localized, and single faults generally affect only one node. Besides, the common central unit can be settled in

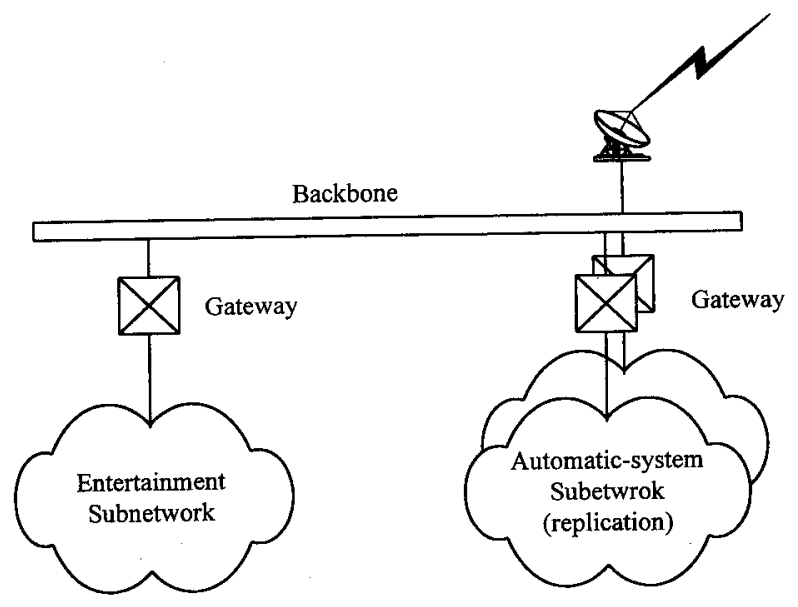

Fig. 2. The proposed network topology of the shipboard LAN.

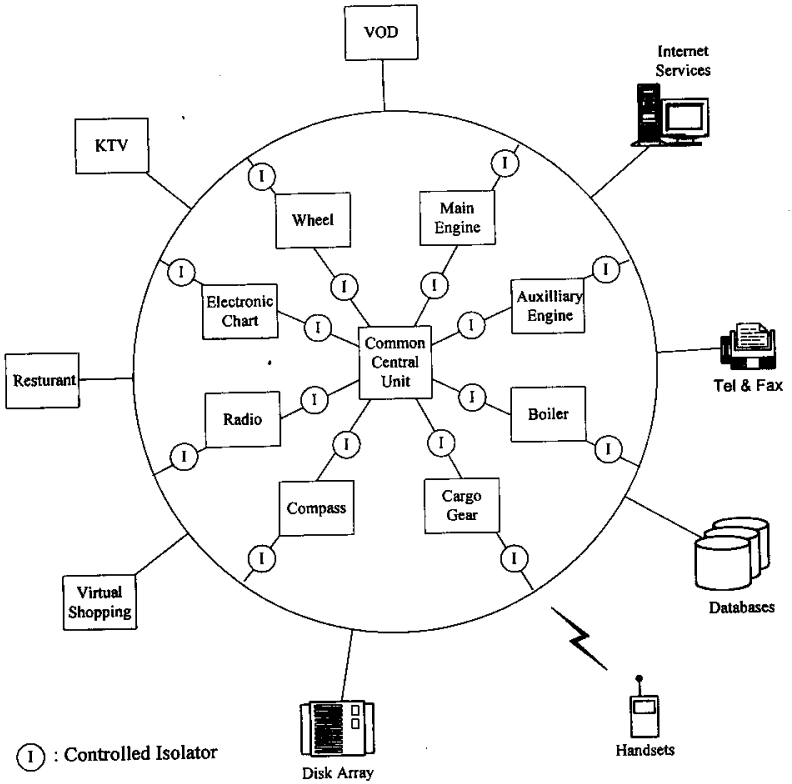

Fig. 3. An example for the design of the shipboard LAN.

the bridge which is often the operation center in most of the merchant ships. The ring subnetwork can be treated as the entertainment subnetwork. Note that all of the automatic systems are connected to both the star and ring subnetworks, via controlled isolators, for the benefit of survivability. The ring subnetwork can be used to back up the star subnetwork, when once the star subnetwork is collapsed or one of the links is broken. Under fault situations, the network is dynamically reconfigured to attain survivability by changing the state of the controlled isolators. On the other hand, the whole network topology can be treated as an FDDI-like system if the common central unit is replaced by a hub switch which perform the operation as a ring.

\section{INTERNETWORKING WITH THE INTERNET}

An estimated 30 million users have access to the Internet, and the number of users is growing at an exponential rate [11]. By the year 2000, 100 million Internet hosts are expected, and each host can serve from one to several hundred people. The rapid growth of the Internet and the moves to create a global information superhighway clearly point to a future mass business and demand for broadband data services. Currently, the Internet provides many services such as WWW, Gopher, FTP, Archie, Usenet News, E-mail, etc. For the importance of the Internet, the disconnection of Internet is not accessible for anyone even at sea. Therefore, it is necessary to intercon- 
nect the shipboard LAN with the Internet.

There are three ways to deliver messages between the shipboard LAN and the terrestrial networks. The first is via the satellite communication, another is via the radio communication, e.g. VHF and MF radios, and the other is via the cellular mobile communication on land. From the view point of spent fees, which transmission method to be adopted depends on the distance to the seacoast. For the cheap cost, the cellular mobile communication should be superior to the others. The cellular mobile communication is evolving in two different directions: microcells and macrocells [12]. Microcells with very small coverage areas are not applicable to the communication between the ship and the shore. On the other hand, macrocell base stations are always built to be capable of covering highways running through low population-density regions between cities. Since macrocells are designed for land-based services, the coverage sea area is limited; therefore, the macrocell radio is not suitable for communications either even in the seacoast.

The satellite communications are suggested to be adopted at the Sea Area A3 defined by the Global Maritime Distress and Safety System (GMDSS). The sea area in which one or more coast stations provide both VHF digital selective calling and radiotelephony services is called Sea Area A1. The Sea Area A2 is defined as the sea area where one or more coast stations provide both MF digital selective calling and radiotelephony services, excluding area A1. The sea area where Inmarsat satellite coverage of 5 degrees elevation or better is available, excluding areas A1 and A2, is called Sea Area A3. For the coverage area of Sea Area A3 is the largest, we will focus on the satellite communications hereafter. The most frequently adopted world-wide satellite communications system at sea is the International Maritime Satellite (INMARSAT) system.

\subsection{The Inmarsat system}

The Inmarsat system provides global satellite communications for maritime community since 1979 , and today the Inmarsat organization is the only provider of world-wide mobile satellite communications for commercial, distress and safety applications on land, at sea and in the air. At sea, the Inmarsat satellites support the services such as direct-dial telephone, telex, facsimile, and data connections. The Inmarsat organization offers Inmarsat-A, Inmarsat- $B$, Inmarsat- $M$, and Inmarsat- $C$ services at sea, and the individual provided service types and data transmission rates are described as follows.
- The Inmarsat-A provides analog communications, and the standard data transmission rate is $9.6 \mathrm{kbps}$. However, a number of models of Inmarsat-A terminals featured a High Speed Data (HSD) option are capable of supporting data rates of up to 64 $\mathrm{kbps}$, which are able to interconnect to the ISDN B channel on land, for the transmission of still and compressed video pictures, high-quality audio and videoconferencing.

- The Inmarsat-B system which extends the advantages of modern digital technology to the field of satellite communications supports a similar range of services as Inmarsat-A, but is cheaper to use. Inmarsat-B is the successor to Inmarsat-A.

- The Inmarsat-M terminals provided $2.4 \mathrm{kbps}$ data connections are portable and user charges are significantly less than those for Inmarsat-A and Inmarsat-B.

- The Inmarsat-C system provides two-way storeand-forward messaging and operates at an information rate of $600 \mathrm{bps}$. Of course, the Inmarsat-C service is the cheapest.

\subsection{Interconnection via Inmarsat}

The Inmarsat system is the best candidate to interconnect the shipboard LAN with the Internet. As shown in Fig. 4, at least two gateways are needed to perform the protocol conversion: a land gateway for the conversion between Internet and Inmarsat, and a shipboard gateway for that between Inmarsat and the shipboard LAN. For the reason of resource sharing and the reduction for the costs of satellite communications, the bandwidth for the Inmarsat communication is shared by all hosts and users in the shipboard LAN by multiplexing. Now we explain the operation procedure for data transmission from the shipboard LAN to the Internet. The shipboard gateway first converts the data which is to be sent to the Internet according to the NMEA-0183 standard defined by the National Maritime Electronics Association (NMEA). Then the converted data is delivered to the Inmarsat terminal, or the Ship Earth Station (SES), on the ship by multiplexing. The SES

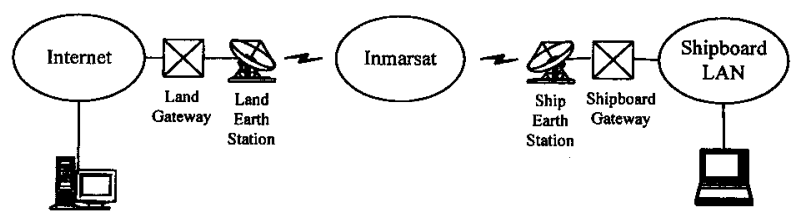

Fig. 4. The internetworking of the shipboard LAN and the Internet via the Inmarsat. 
then transmits the data to the Inmarsat Land Earth Station (LES), sometimes called the Coast Earth Station (CES) via the Inmarsat satellite communications. After receiving the data from the LES, the land gateway converts the data format and delivers the data to the Internet. The operation for data transmission from Internet to the shipboard LAN is the same as the above procedure except that the sequence is opposite.

The Internet consists of a number of interconnected networks supporting communications among host computers using many Internet protocols, such as the Internet Protocol (IP) and the Internet Control Message Protocol (ICMP), and a variety transport and application protocols that depend on them. According to RFC-1009, RFC-1716 and RFC-1812 [13$15]$, the protocols which a gateway needs to implement at least includes:

-Address Resolution Protocol (ARP)

-Ethernet \& 802.3 Coexistence

-Point-to-Point Protocol (PPP)

-Internet Protocol (IP)

-Internet Control Message Protocol (ICMP)

- User Datagram Protocol (UDP)

-Transmission Control Protocol (TCP)

- Open Shortest Path First (OSPF)

-Inter-Routing-Protocol Information Exchange

-Simple Network Management Protocol (SNMP)

-Internet Group Management Protocol (IGMP)

For the gateways connected to the Inmarsat, it is difficult to implement the above protocols, other efficient gateway functions and many frequently used Internet protocols, such as Hypertext Transfer Protocol (HTTP) and NetNews Transfer Protocol (NNTP), utilizing the technology of client/server. For the high cost of satellite communications, less data transmission over the Inmarsat system is expected. Therefore, three concepts to reduce the amount of data transmission across satellite communications are proposed:

(1) The amount of information provided in the shipboard LAN have to be as much as possible, so that the passengers and mariners are able to obtain the required information directly from the shipboard LAN instead of satellite data communications. Therefore, it is necessary to build many servers in the shipboard LAN.

(2) Due to the finite storage capacity of the shipboard servers, another problem is which kind of information has to be stored, so that the information required by the passengers can be satisfied possibly, and thus the amount of satellite communications is reduced. By statistics, the information which is often read is prior to be stored in the shipboard servers.

(3) For the Internet services based on the concept of client/server, the client agent must be designed to have more powerful capability as possible. For the situation that the satellite communications can not be avoided, a powerful client is able to maintain much more amount of the past retrieved information to prevent the information ever being retrieved from retransmissions. Besides, the capability of graphics, compression and decompression for the client agent also have to be improved so that the amount of satellite data communications is the least. For example, a recently released version of the Mosaic Windows-based Internet browser will operate at 14.4 kbps. The speed exceeds the maximum data rate of the Inmarsat- $M$ service, but the gap will eventually bridged as the powerful client is developed.

Among the Internet services, the electronic mail is currently the simplest one to be implemented dacross the Inmarsat satellite communications. Thus, we focus on the electornic mail (e-mail) service hereafter.

\subsection{Electronic mail service on board}

Electronic mails have become one of the most frequently used services in the Internet. People always check their own electornic mailboxes everyday through the traditional telecommunication networks, and the cost is vry cheap and even free in some academic networks. However, the high cost of the satellite communications will discourage the passengers or mariners at sea from the useless e-mail checks. That is, it is not suggested for the passengers to check, via the satellites, whether there is any e-mail in his mailbox or not, since the pssengers still have to pay the fees for the satellite communciations even though the mailbox is empty. Therefore, it is necessary to have an effective policy to automatically forward e-mails from the host habitually used by the passengers to the shipboard LAN, and the passengers do not need to take the risk of asking the satellite communication to check the empty mailbox. We now propose a policy explained as follows for the e-mail forwarding from the internet host to the shipboard LAN.

(1) The passenger gives his habitual e-mail address to the ship company when he buys or preserves the ticket.

(2) The ship company assigns a common e-mail address to all passengers, and the passenger sets up the environment in his habitual host so that 
all of his newly arriving e-mails will be forwarded to the common e-mail address via the Internet. For example, in an UNIX system the only thing to be done is that putting the common e-mail address to the content of the file forward in the home directory.

(3) The mail server of the ship company have to maintain a table, called the $e$-mail routing table, which indicates the relationships among the name and e-mail address of each passenger, the name and position of the ship, and the identification number of the Inmarsat SES, equipped on the shipboard, where the Inmarsat identification number is an unique number identifier named by the Inmarsat organization, and is either the mobile earth station identification number (MESIN) for an Inmarsat-B, Inmarsat-C, Inmarsat$M$ and all new Inmarsat SES, or the ship earth station identity number (SESIN) for an InmarsatA SES.

(4) The header of each e-mail arrived in the common e-mail address will be parsed so that the mail server is able to know where this e-mail is forwarded from. The mail server then searches the e-mail routing table to obtain the name of the passenger who owns the e-mail, the name and position of the ship taken by the passenger, and the MESIN or SESIN of the Inmarsat SES.

(5) Then via the Internet, the mail server forwards the e-mail to the Inmarsat LES. The header of the forwarded e-mail must include the identification number of the Inmarsat SES and the passenger's name. Note that more than 34 LESs around the world are focused on the satellite, and the LES located on the same ocean region as the ship is chosen.

(6) The chosen LES plays the role of the gateway between the Internet and the Inmarsat system. After receiving the e-mail from Internet, the chosen LES parses the e-mail to get the MESIN or SESIN, converts the format of the e-mail according to the NMEA-0183 standard, and then transmits the e-mail to the SES via the Inmarsat satellite communications.

(7) The SES on board also plays the role of the gateway between the Inmarsat satellite system and the shipboard LAN. The received e-mail will be sent to the passenger's account through the shipboard LAN.

Note that only step 6 needs to pay the fees for the Inmarsat system, and other steps across the Internet are free or cheap. The procedure for delivering emails from the shipboard LAN to the Internet is just opposite to that described in the above.

\section{SUMMARY AND FUTURE WORKS}

A shipboard LAN is capable of not only integrating all of the automatic systems on the merchant ship, but also providing many services, such as VOD, KTV and virtual shopping, for the passengers and the mariners. Therefore, it is necessary to build a shipboard LAN on the ship. Moreover, by interconnecting the shipboard LAN with the Internet via the Inmarsat system, Internet services are also accessible at sea. Besides, through the interconnection, remote control by the experts and specialists on land is available to fix the breakdown of engines, machines and instruments on the ship. In the paper, a template for the shipboard LAN is designed from the view point of survivability and traffic types. Three concepts to reduce the satellite communication cost are proposed, and the way to implement the electronic mails, the most possible realized Internet service, is also proposed.

However, a number of problems for the internetworking via the Inmarsat system still have to be overcome. For example, the methods to develop client/server-based softwares with strong client agents for low communication costs, and the way to design gateways with high switching capacity and high efficiency among the Inmarsat system, the Internet and the shipboard LAN, are still open issues. Moreover, a wireless shipboard LAN may enhance its survivability, but video services, which need a lot amount of bandwidth, are difficult to be provided over the wireless LAN.

\section{ACKNOWLEDGMENT}

The authors would like to thank the anonymous reviewers for their constructive criticisms and suggestions.

\section{REFERENCES}

1. 熊雲風, Fundamentals of Marine Control Engineering and Automation in Merchant Ships, 徐氏期金會 (1990).

2. A.-B. Liu, The Effectiveness of Marine Simulator Training by Discussing the Automation of Merchant Ship, 華成出版社 (1992).

3. A.S. Tanenbaum, Computer Networks, 2nd Ed., Prentice-Hall International, Inc. (1989).

4. P. Joshhi, "High-performance networks: A focus on the Fiber Distributed Data Interface (FDDI) standard," IEEE Micro, Vol. 6, No. 3, pp. 8-14, June (1986).

5. R. Handel, M.N. Huber and S. Schroder, ATM Net- 
works: Concepts, Protocols, Applications, 2nd Ed., Addison-Wesley publishing company (1994).

6. A. Hac and A.B. Mutlu, "Synchronous optical network and broadband ISDN protocols," Computer, Vol. 22, No. 11, pp. 26-34, Nov. (1989).

7. R. Handle, "Evaluation of ISDN toward broadband ISDN," IEEE Network Magazine, Vol. 3, No. 1, pp. 713, Jan. (1989).

8. Y.-H. Chang, D. Coggins, D. Pitt, D. Skellern, M. Thaper, and C. Venkatraman, "An open-systems approach to video on demand," IEEE Communications Magazine, pp. 68-80, May (1994).

9. R. L. Scott, "Geoscience resources on the Internet", Reference Librarians, No. 41-42, pp. 55-63 (1994).

10. J. E. Cooling, "Survivable LANs for distributed control systems," Computer Communications, Vol. 17, No. 5, pp. 317-331, May (1994).

11. B. Gallagher, "The information superhighway: racetrack or ring road," Asia-Pacific Telecommunity Journal, Jan. (1995).

12. D. C. Cox, "Wireless personal communications: What is it?," IEEE Personal Communications, pp. 20-35, Apr. (1995).

13. R. Braden and J. Postel, Requirements for Internet gateways, Request for Comments (RFC) 1009, June (1987).

14. P. Almquist and F. Kastenholz, Towards Requirements for IP Routers, Request for Comments (RFC) 1716, Nov. (1994).

15. F. Baker, Requirements for IP Version 4 Routers, Request for Comments (RFC) 1812, June (1995).

\section{網路整合船舶自動化系統及其與} Internet之互連

周 立 德

中華工事院資部工毫系

耗 政 義

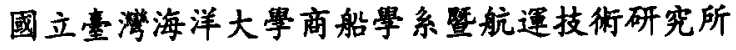

$$
\text { 摘 要 }
$$

在商船自動化的領域中, 部多的船舶自動化 系統不断地發展出来, 以期进到機觝無人化 (Unmanned Machinery Space)之目的。因此極有必 要在船舶中建置一區域網路, 將這些船舶自動化系 統加以整合。此外，此一船舶區域網路更可經由 Inmarsat街星系統與陸上通信網路（例如Internet） 互連, 以提供全球性的通信服務。本端文設计一具 有存活性(Survivability)的船舶區域網路, 並提出三 個建置船舶區域網路之梘點，以降低船舶區域綢路 與Internet互速時所需之街星通信费用。我們最後提 出䋑由Inmarsat系统提供電子郵件服務的辛施方 式。 